\title{
The Mechanism of the Acid-Catalyzed Decomposition of Dicumyl Peroxide in Dodecane: The Intermediacy of Cumene Hydroperoxide
}

\section{Supporting Information}

Mark Conley ${ }^{1,3}$, Fiaz S. Mohammed ${ }^{1,3}$, Charles Winslow ${ }^{1}$, Harris Eldridge ${ }^{1}$, Jeffrey M. Cogen ${ }^{4}$, Bharat I. Chaudhary ${ }^{4}$, Pamela Pollet ${ }^{2,3}$, and Charles L. Liotta*1,2,3

${ }^{1}$ School of Chemical and Biomolecular Engineering; Georgia Institute of Technology; 311 Ferst St; Atlanta, GA 30332-0100 (USA)

${ }^{2}$ School of Chemistry and Biochemistry; Georgia Institute of Technology; 911 Atlantic Dr; Atlanta, GA 30332 (USA)

${ }^{3}$ Specialty Separations Center; Georgia Institute of Technology; 311 Ferst St; Atlanta, GA 30332-0100 (USA)

${ }^{4}$ The Dow Chemical Company; 400 Arcola Road, Collegeville, PA 19426

*Corresponding Author: Fax (+1) 404-385-3210 Email: charles.liotta@chemistry.gatech.edu

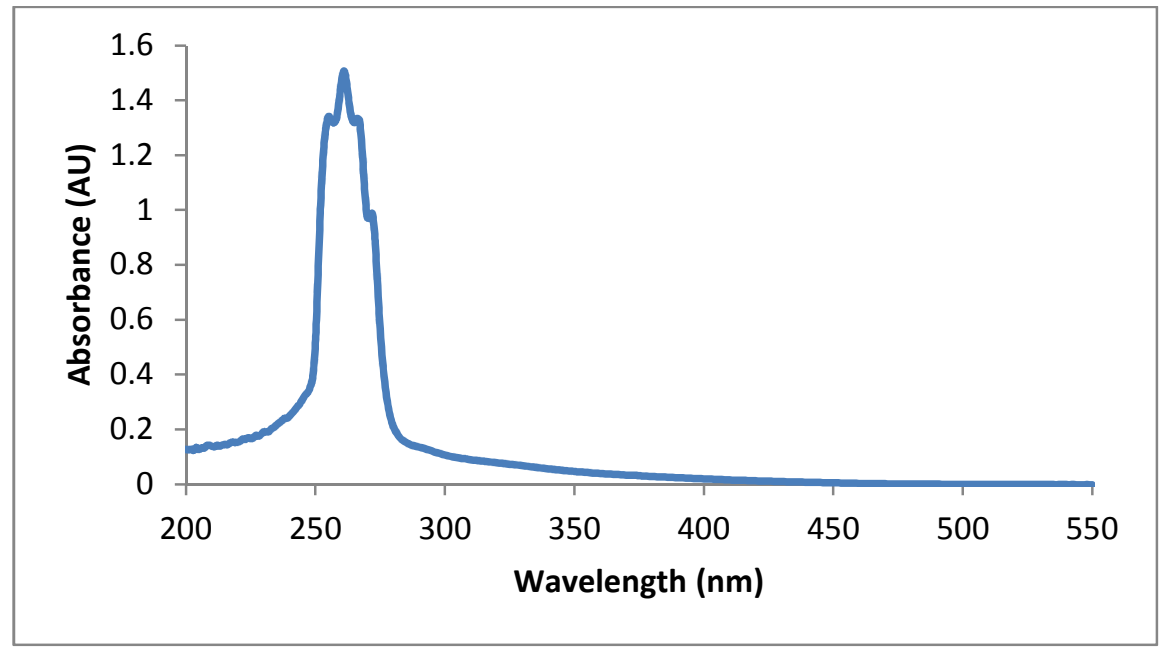

Figure S1. UV-Vis absorbance of 0.002 M DBSA in dodecane. The absorbance spectrum of a standard sample of dodecane was subtracted to produce the plot above. 


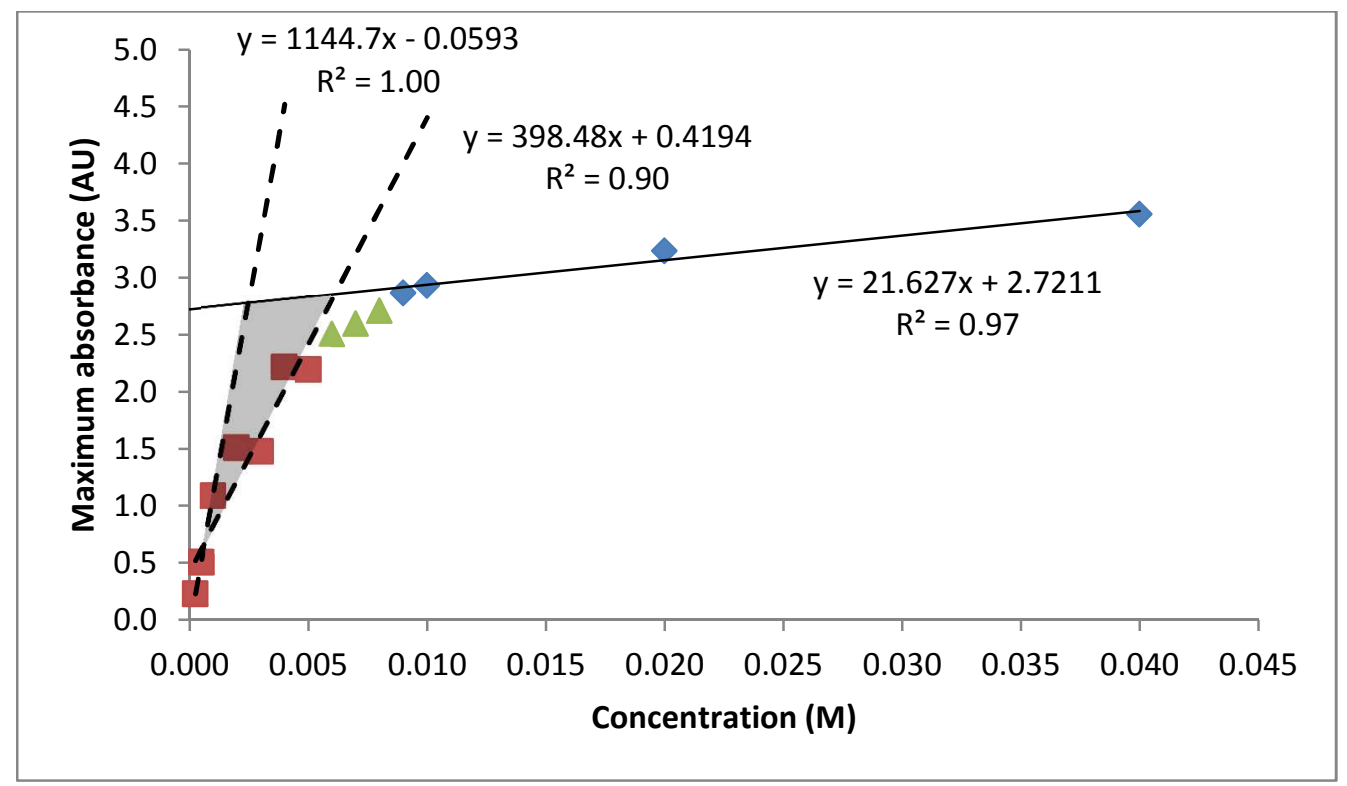

Figure S2. Maximum absorbance from UV-Vis spectra of DBSA in dodecane as a function of concentration. The critical micelle concentration was taken to be in the gray range of the intersection of the fit lines shown.

The CMC for DBSA in dodecane was taken to be the intersection of the fit lines from the two regimes of absorbance concentration dependence. The lines for the regime of low concentration have different slopes, depending on the selection of points used to fit the lines. We assess that the CMC is within the region shaded in Figure S2, between the bounds of $0.0025 \mathrm{M}$ and $0.006 \mathrm{M}$ DBSA (0.042 molar equivalents of DCP and 0.10 molar equivalents of $0.0589 \mathrm{M} \mathrm{DCP}$ ) in dodecane. In this paper, we run reactions with DBSA concentrations above and below the CMC. However, kinetics experiments were done with DBSA below the CMC, as formation of micelles would confound the results of any rate determination experiments. 


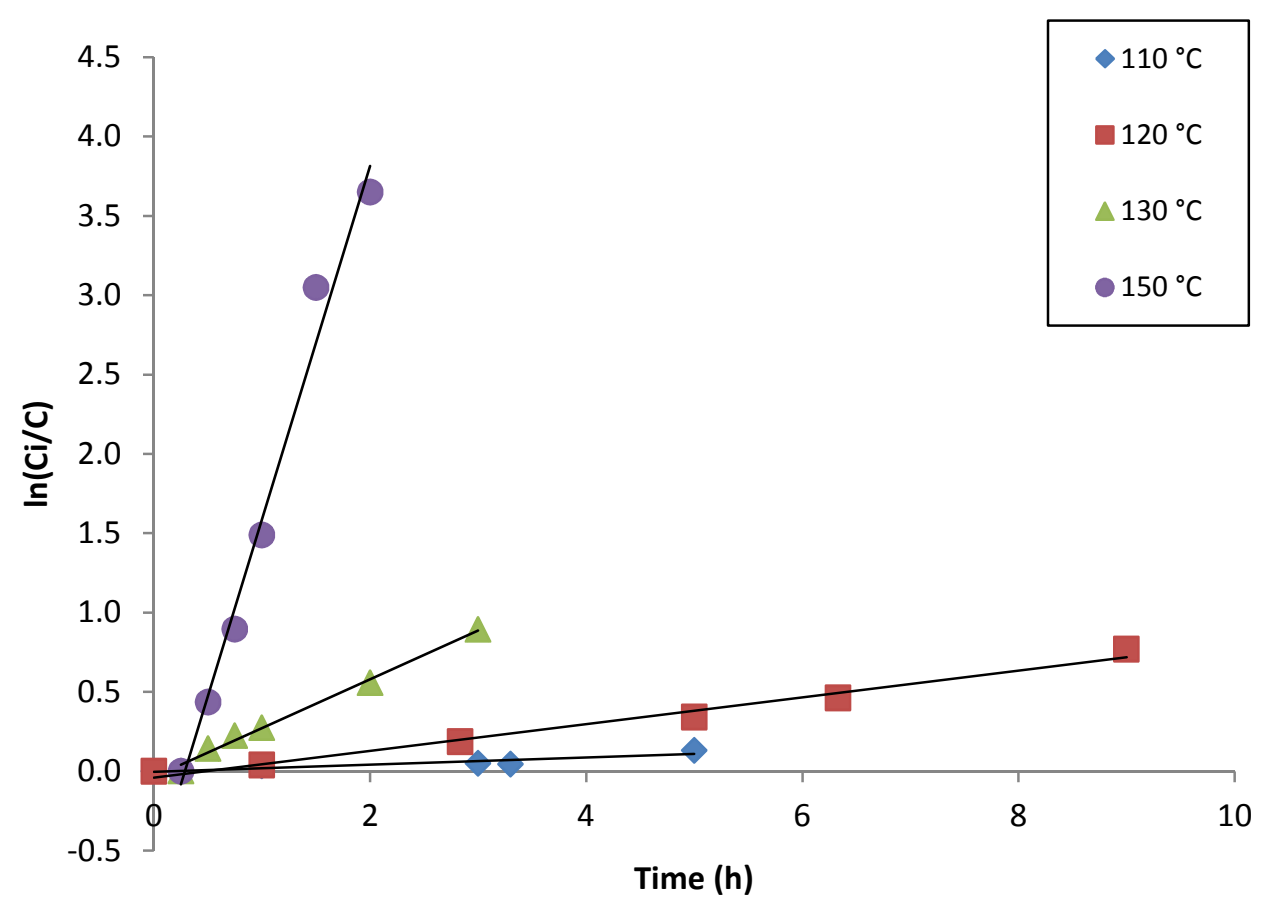

Figure S3. First-order plots for the thermal decomposition of 0.321 M DCP in dodecane. 


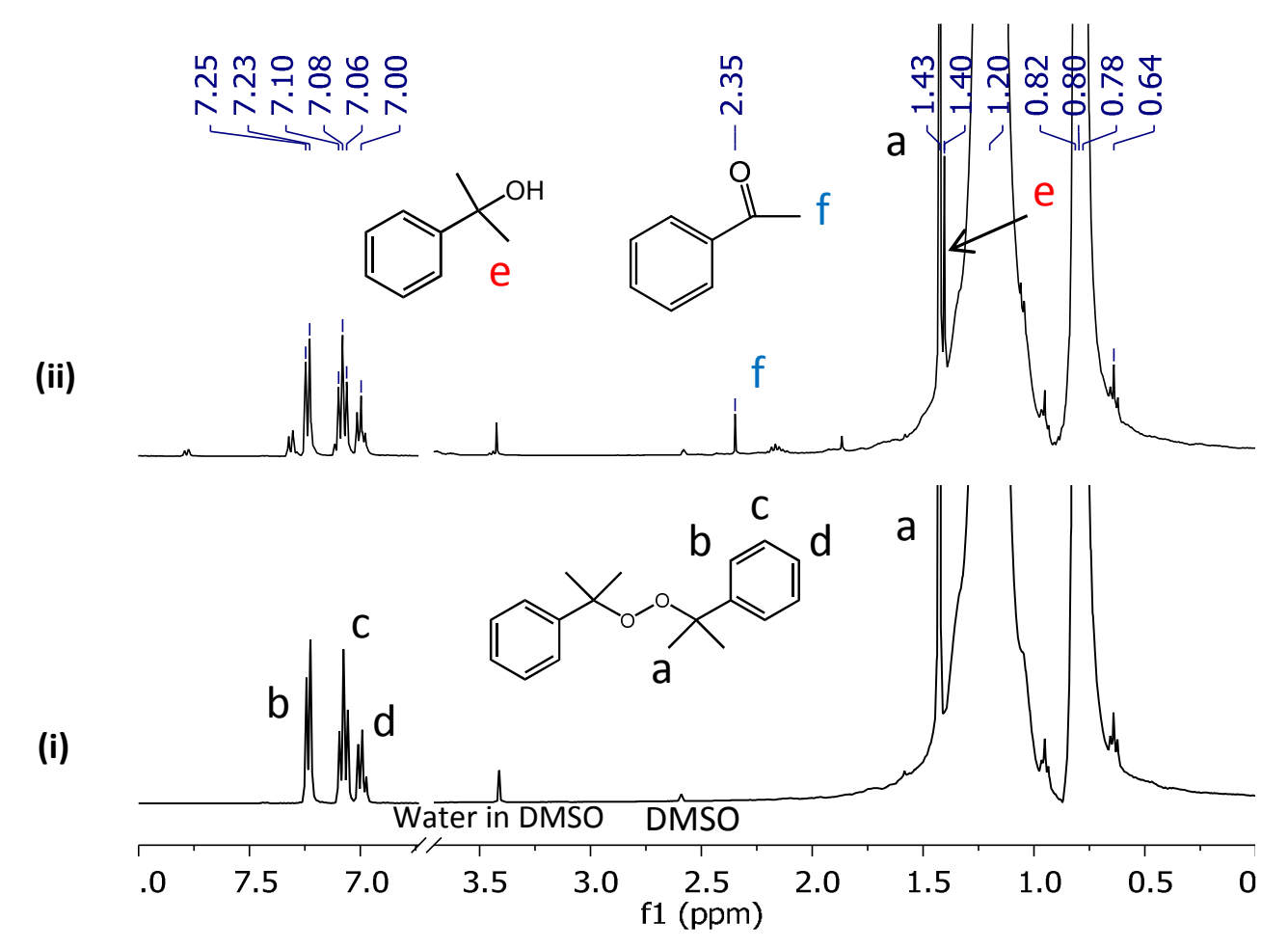

Figure S4. Proton NMR spectrum of the thermal decomposition of $0.0589 \mathrm{M}$ DCP in dodecane at $120{ }^{\circ} \mathrm{C}$. (i): reaction mixture before heating. (ii): reaction mixture after 3.5 hours at $120^{\circ} \mathrm{C}$. These spectra were taken of the undiluted reaction solution with a capillary of DMSO-d6. The large aliphatic peaks are dodecane. At $120{ }^{\circ} \mathrm{C}$ the data indicates that the half-life of DCP is approximately 9 hours. After 3.5 hours, approximately $30 \%$ of the DCP has thermally decomposed. Figure S4ii clearly shows the formation of acetophenone and cumyl alcohol. The peak at $2.40 \mathrm{ppm}$ is assigned to the methyl hydrogens of acetophenone and the peak at $1.40 \mathrm{ppm}$ is assigned to the methyl groups of cumyl alcohol. Since only approximately $30 \%$ reaction has taken place, there remains a substantial amounts of unreacted DCP as shown by the peak at $1.43 \mathrm{ppm}$.

The protons associated with the four methyl groups of DCP are clearly visible at $1.43 \mathrm{ppm}$ (labeled ' $a$ ' in Figure S4ii). The two major products formed in the reaction are ACP (the methyl protons thereof are located at $2.35 \mathrm{ppm}$, labeled ' $\mathbf{f}$ ' in Figure S4ii) and CA (the protons of the two methyl groups are located at $1.40 \mathrm{ppm}$, labeled ' $\mathbf{e}$ ' in Figure S4ii). All assignments are consistent with those reported in literature. $^{3}$ 


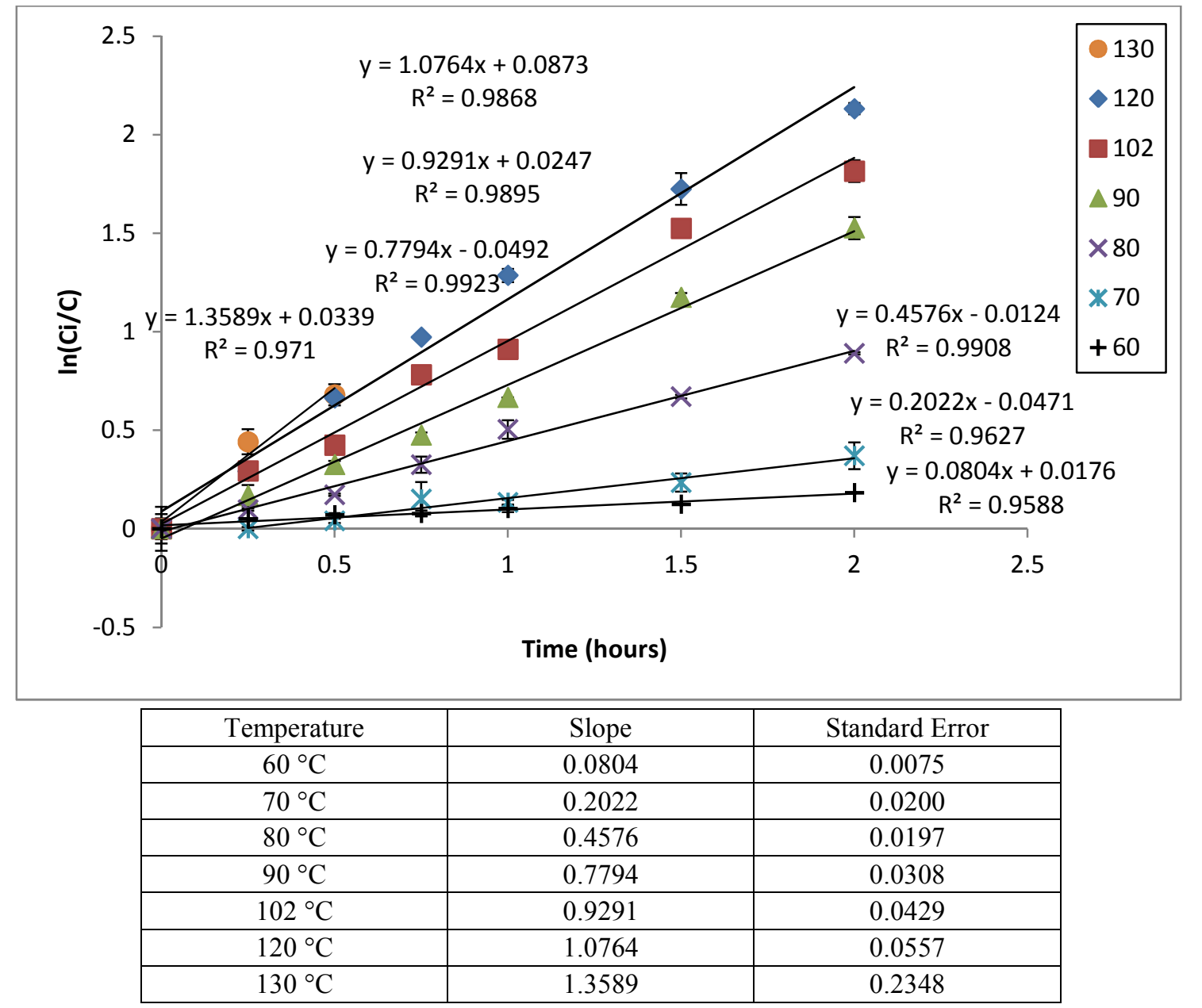

Figure S5. First-order plots for the reaction of 0.0589 M DCP with 0.03 equivalents of DBSA as a function of temperature. Standard errors associated with the slopes are presented in the table. 

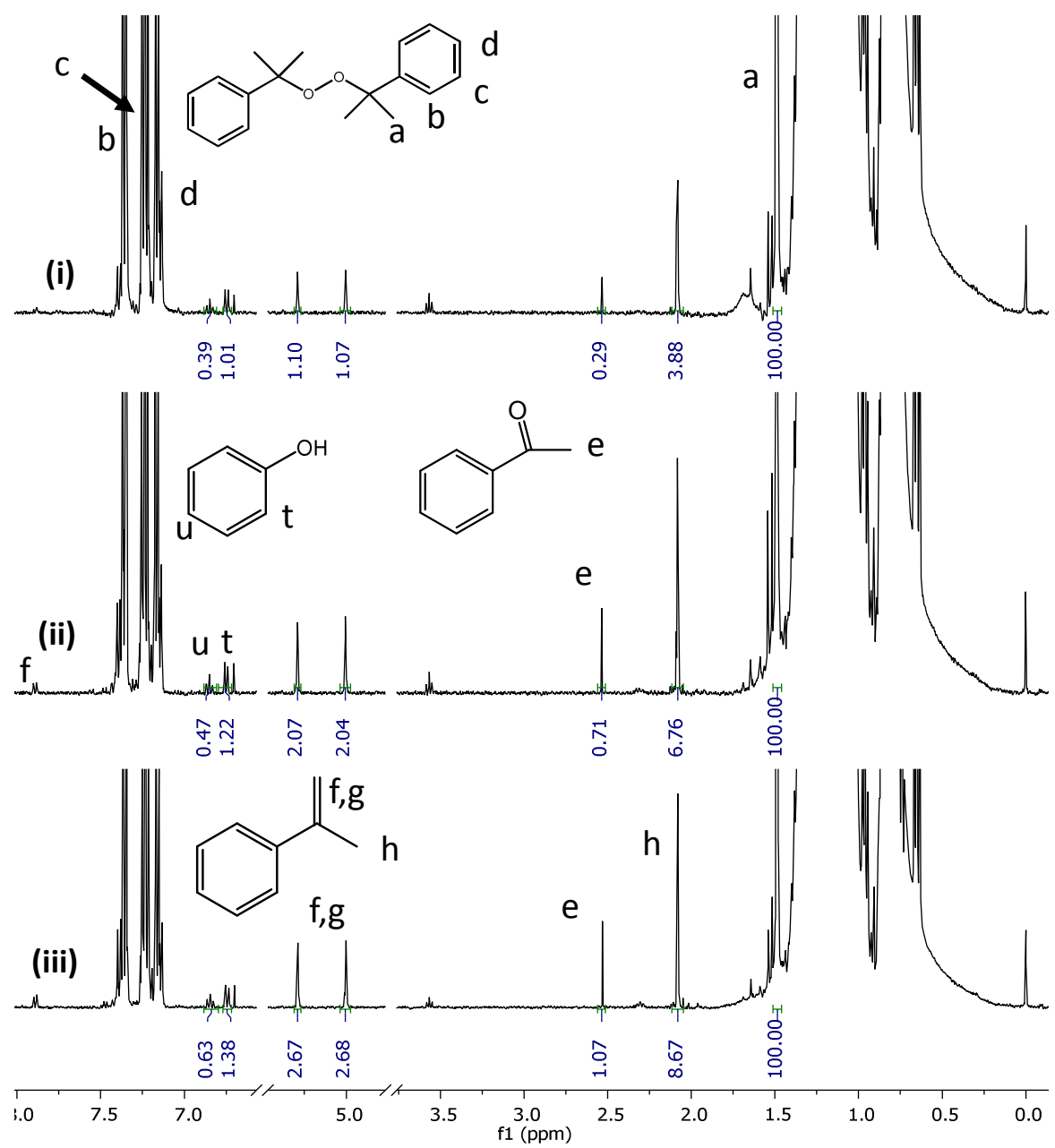

Figure S6. Proton NMR spectra of the acid-catalyzed decomposition of DCP. Reaction run with 0.03 molar equivalents (relative to DCP) DBSA (0.00177 $\mathrm{M}$ DBSA) at $120^{\circ} \mathrm{C}$ in dodecane. (i): spectrum after 15 minutes of reaction. (ii): spectrum after 30 minutes of reaction. (iii): spectrum after 45 minutes of reaction. No significant change is observed after after 30 minutes; the reaction is essentially complete.

${ }^{1} \mathrm{H}$ NMR spectra of the acid-catalyzed reaction at $120{ }^{\circ} \mathrm{C}$ are shown at 15 minutes (i), after 30 minutes (ii), and after 45 minutes (iii) in Figure S6. DCP and ACP have the same shifts as shown in Figure S4 and their characteristic peaks are labeled ' $\mathbf{a}$ ' and ' $\mathbf{e}$ ' in Figure S6. Consistent with Figure 2, the formation of $\alpha$-methyl styrene (vinyl proton shifts of $5.0 \mathrm{ppm}$ and $5.27 \mathrm{ppm}$, labeled ' $\mathbf{f}$ ' and ' $\mathrm{g}$ ' in Figure S6; methyl proton shift of $2.12 \mathrm{ppm}$, labeled ' $\mathbf{h}$ ' in Figure S6) is observed. Phenol is also observed; a triplet is seen at $6.71 \mathrm{ppm}$ (labeled ' $\mathbf{u}$ ' in Figure S6) and a doublet is seen at $6.50 \mathrm{ppm}$ (labeled ' $\mathbf{t}$ ' in Figure S6). No CA is visible via NMR, which is consistent with the acid-catalyzed dehydration of the alcohol to $\alpha$-methyl styrene. From the integrated areas (with the methyl peak of DCP ' $a$ ' set to 100 in all spectra) it can be seen that the proportions of phenol, ACP, and AMS increase relative to DCP as a function of time. 

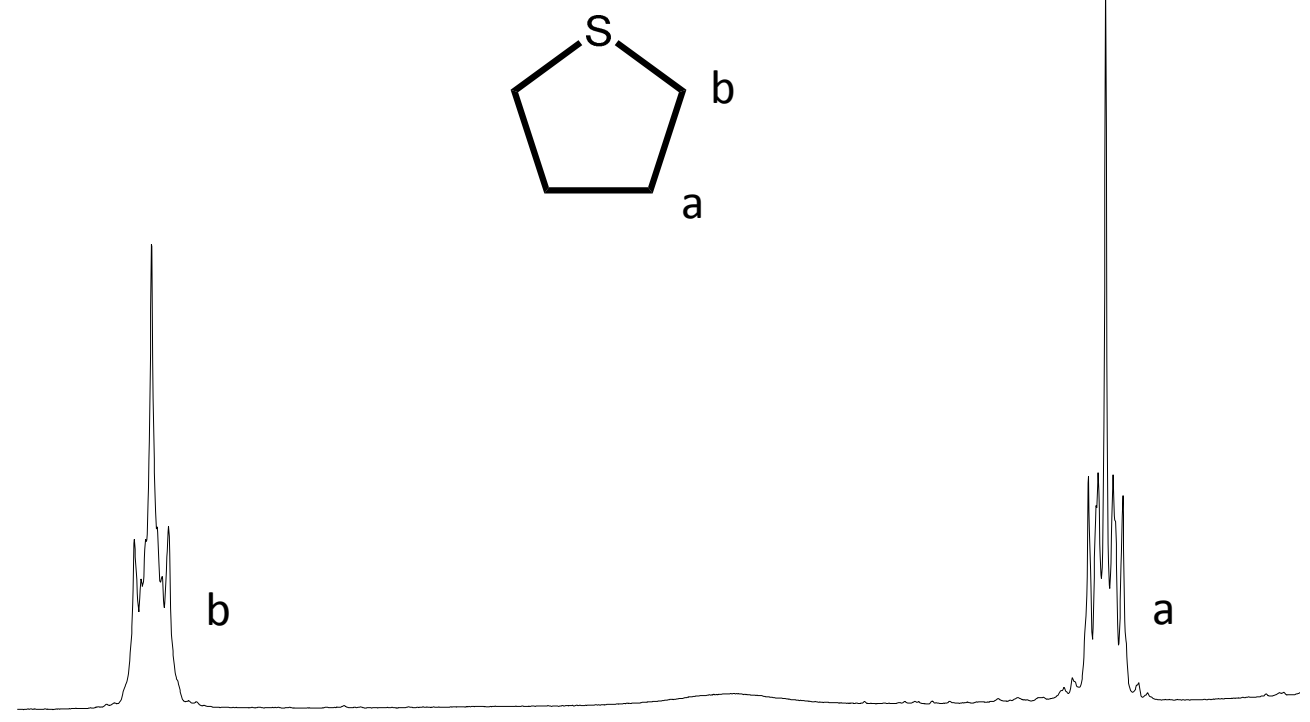

$\begin{array}{lllllllllllllllllllllllll}00 & 2.95 & 2.90 & 2.85 & 2.80 & 2.75 & 2.70 & 2.65 & 2.60 & 2.55 & 2.50 & 2.45 & 2.40 & 2.35 & 2.30 & 2.25 & 2.20 & 2.15 & 2.10 & 2.05 & 2.00 & 1.95 & 1.90 & 1.85\end{array}$

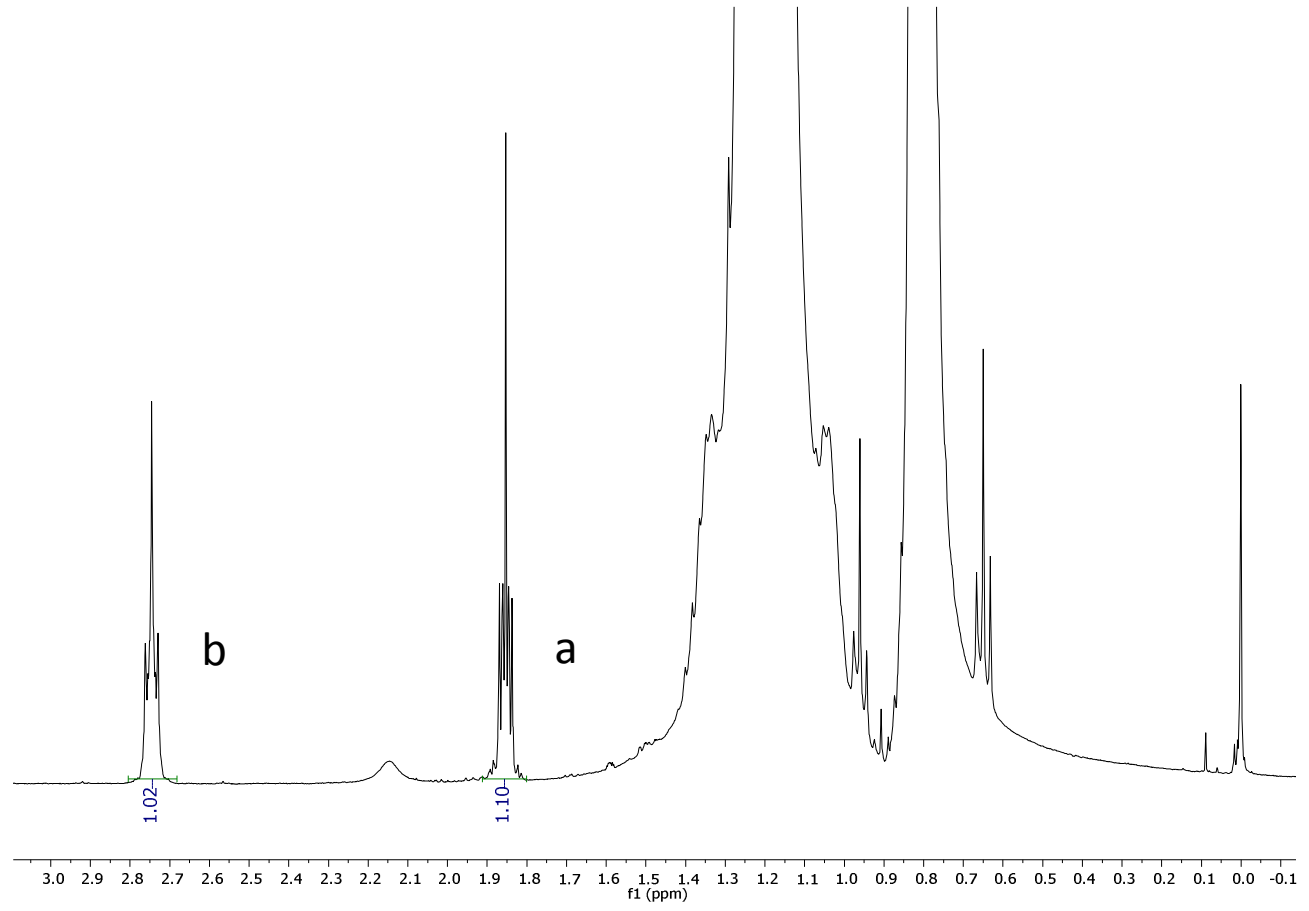

Figure S7. ${ }^{1} \mathrm{H}$ NMR spectrum of the reaction of $0.0589 \mathrm{M}$ THTP with 0.03 molar equivalents of DBSA in dodecane at 120 ${ }^{\circ} \mathrm{C}$ for 2 hours. No reaction is observed. Peaks ' $a$ ' and ' $b$ ' correspond to THTP alone. The large peaks between 0.5 ppm and $1.6 \mathrm{ppm}$ arise from both dodecane and DBSA.

THTP has proton shifts of 1.9 ppm (labeled 'b') and 2.8 ppm (labeled 'a'), seen in Figure S7 above. 

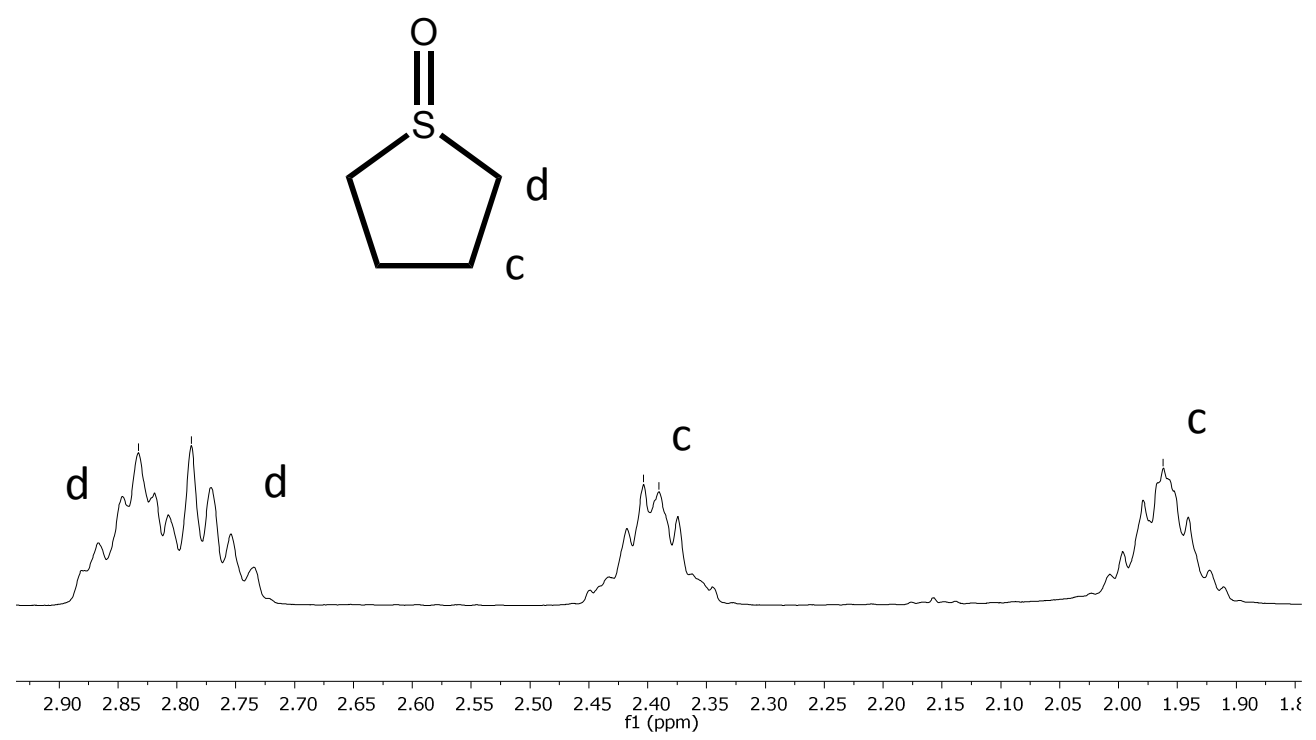

Figure S8. Proton NMR shifts and structure of tetrahydrothiophene-1-oxide. Spectrum was taken in $\mathrm{CDCl}_{3}$.

The sulfoxide oxidation product THTP-1-oxide exhibits 3 proton peaks because the protons nearest the sulfoxide group are enantiotopic with shifts of $2.05 \mathrm{ppm}$ and $2.45 \mathrm{ppm}$ (labeled 'c' in Figure S8 above). The remaining protons of the sulfoxide product have a shift of 2.75-2.90 ppm (labeled ' $\mathbf{d}$ ' in spectrum (ii) above). 


$$
\begin{aligned}
& \mathrm{DCP}+\text { DBSA } \stackrel{\mathrm{k}_{1}}{\rightleftharpoons} \text { complex } \\
& \mathbf{k}_{-1} \\
& \text { complex } \stackrel{k_{2}}{\longrightarrow} \text { DBSA }+ \text { products } \\
& \frac{d[\text { complex }]}{d t}=k_{1}[D C P][D B S A]-k_{-1}[\text { complex }] \\
& -k_{2} \text { [complex] } \\
& \text { set } \frac{d[\text { complex }]}{d t}=0 \\
& {[\text { complex }]=\frac{k_{1}[D C P][D B S A]}{k_{-1}+k_{2}}} \\
& \frac{d[D C P]}{d t}=-k_{1}[D C P][D B S A]+k_{-1}[\text { complex }] \\
& \frac{d[D C P]}{d t}=-k_{1}[D C P][D B S A]+k_{-1}\left[\frac{k_{1}[D C P][D B S A]}{k_{-1}+k_{2}}\right] \\
& -\frac{d[D C P]}{d t}=\frac{k_{2} k_{1}}{k_{2}+k_{-1}} *[D B S A] *[D C P] \\
& -\frac{d[D C P]}{d t}=k_{e f f} *[D C P] \\
& k_{e f f}=\frac{k_{2} k_{1}}{k_{2}+k_{-1}} *[D B S A]
\end{aligned}
$$

Figure S9. Derivation of the pseudo-first order rate expression for the acid-catalyzed decomposition of DCP. 
(a)

We first define the total amount of phenol produced in terms of the integral (over the course of the entire reaction) of the derivative of the phenol concentration as a function of time. The prime (') notation is used as a shorthand for the derivative with respect to time.

$$
[\text { phenol produced }]=\int_{0}^{t} \frac{d[\text { phenol }]}{d t} d t=\int_{0}^{t}[\text { phenol }]^{\prime} d t
$$

From Figure 14, we can see that phenol is produced both directly from DCP and also from the intermediate CHP. The term for the production of phenol, [phenol]', is correspondingly separated into two terms.

$$
[\text { phenol produced }]=\int_{0}^{t}[\text { phenol }]_{D C P}^{\prime} d t+\int_{0}^{t}[\text { phenol }]_{C H P}^{\prime} d t
$$

where [phenol]' ${ }_{\mathrm{DCP}}$ is the rate of phenol produced directly from DCP and [phenol]' ${ }_{\mathrm{CHP}}$ is the rate of phenol produced directly from CHP.

After the formation of the hydrogen-bonded complex, DCP can decompose via either $\mathrm{k}_{2}$ ' or $\mathrm{k}_{2}$ '". Since phenol is produced via $\mathrm{k}_{2}$ ', we can rephrase [phenol]' ${ }_{\text {DCP }}$ in terms of the DCP that decomposes via only the $\mathrm{k}_{2}$ " pathway. The negative sign appears because DCP is a reactant while phenol is a product.

$$
[\text { phenol produced }]=\frac{k_{2}^{\prime \prime}}{k_{2}^{\prime}+k_{2}^{\prime \prime}} \int_{0}^{t}-\frac{d[D C P]}{d t} d t+\int_{0}^{t}[\text { phenol }]_{C H P}^{\prime} d t
$$

If we measure from the start to the end of reaction, the integral of the rate of DCP consumption simply becomes the total amount of DCP consumed, or the product of $[\mathrm{DCP}]_{0}$ and the conversion of DCP.

$$
[\text { phenol produced }]=\frac{k_{2}^{\prime \prime}}{k_{2}^{\prime}+k_{2}^{\prime \prime}} * X_{D C P} *[D C P]_{0}+\int_{0}^{t}[\text { phenol }]_{C H P}^{\prime} d t
$$

Here, $\mathrm{X}_{\mathrm{DCP}}$ represents the conversion of DCP during the reaction.

We can address the second integral in a similar fashion to the first. Once formed, CHP can decompose via multiple pathways. Since phenol is produced via $\mathrm{k}_{3}$, we can rephrase [phenol]' ${ }_{\mathrm{CHP}}$ in terms of the CHP that decomposes via the $\mathrm{k}_{3}$ ' pathway.

$$
[\text { phenol produced }]=\frac{k_{2}^{\prime \prime}}{k_{2}^{\prime}+k_{2}^{\prime \prime}} * X_{D C P} *[D C P]_{0}+\frac{k_{3}^{\prime}}{k_{3}^{\prime}+k_{4}+k_{-2}} \int_{0}^{t}-\frac{d[C H P]}{d t} d t
$$

Similar to previous steps, we realize that the integral of the rate of CHP consumption from the start to the end of reaction is simply the total amount of CHP consumed, or the product of the concentration of CHP produced during reaction and the conversion of CHP.

$$
[\text { phenol produced }]=\frac{k_{2}^{\prime \prime}}{k_{2}^{\prime}+k_{2}^{\prime \prime}} * X_{D C P} *[D C P]_{0}+\frac{k_{3}^{\prime}}{k_{3}^{\prime}+k_{4}+k_{-2}} * X_{C H P} *[C H P]_{\text {produced }}
$$

where $[\mathrm{CHP}]_{\text {produced }}$ is taken to be the total amount of CHP produced during the course of reaction (not the initial amount of CHP). 
$[\mathrm{CHP}]_{\text {produced }}$ can be expanded: since CHP is formed via $\mathrm{k}_{2}$, we can substitute the term for the total amount of DCP that decomposed via the k2' pathway as shown in the next step.

[phenol produced]

$$
=\frac{k_{2}^{\prime \prime}}{k_{2}^{\prime}+k_{2}^{\prime \prime}} * X_{D C P} *[D C P]_{0}+\frac{k_{3}^{\prime}}{k_{3}^{\prime}+k_{4}+k_{-2}} * X_{C H P} * X_{D C P} *[D C P]_{0} *\left[1-\frac{k_{2}^{\prime \prime}}{k_{2}^{\prime}+k_{2}^{\prime \prime}}\right]
$$

To rearrange and simplify,

$$
\begin{gathered}
{[\text { phenol produced }]=X_{D C P} *[D C P]_{0} *\left\{\frac{k_{2}^{\prime \prime}}{k_{2}^{\prime}+k_{2}^{\prime \prime}}+\frac{k_{3}^{\prime}}{k_{3}^{\prime}+k_{4}+k_{-2}} * X_{C H P} *\left[1-\frac{k_{2}^{\prime \prime}}{k_{2}^{\prime}+k_{2}^{\prime \prime}}\right]\right\}} \\
\text { phenol yield }=\frac{k_{2}^{\prime \prime}}{k_{2}^{\prime}+k_{2}^{\prime \prime}}+\left[1-\frac{k_{2}^{\prime \prime}}{k_{2}^{\prime}+k_{2}^{\prime \prime}}\right] X_{C H P} \frac{k_{3}^{\prime}}{k_{3}^{\prime}+k_{4}+k_{-2}}
\end{gathered}
$$

Note that [phenol produced] has been replaced by "phenol yield," which we define as the amount of phenol produced divided by the total amount of DCP consumed.

We have arrived at the form of Equation 3 presented in the manuscript.

In the manuscript and the above derivation, we have implicitly used the assumption that we can measure the relative proportions of rate constants (i.e., $k_{3}^{\prime} / k_{3}^{\prime}+k_{4}+k_{-2}$ ) by measuring the final product concentrations. The proof of this treatment is presented below.

First, we make the mathematical definition that the final concentration of any species is equal to the integral (from the start to the end of reaction) of the rate of production of that species. The rates of production for these species are expressed as rate constants multiplied by the reactant (CHP) concentration.

$$
\begin{aligned}
& \frac{[\text { phenol }]_{\text {final }}}{[\text { phenol }]_{\text {final }}+[\text { AMS }]_{\text {final }}+[D C P]_{\text {final }}} \\
& =\frac{\int_{0}^{t} k_{3}^{\prime}[C H P](t) d t}{\int_{0}^{t} k_{3}^{\prime}[C H P](t) d t+\int_{0}^{t} k_{4}[C H P](t) d t+\int_{0}^{t} k_{-2}^{\prime}[C H P](t) d t}
\end{aligned}
$$

Now, the rate constants are moved outside of the integrands.

$$
\begin{aligned}
& \frac{[\text { phenol }]_{\text {final }}}{[\text { phenol }]_{\text {final }}+[\text { AMS }]_{\text {final }}+[D C P]_{\text {final }}} \\
& =\frac{k_{3}^{\prime} \int_{0}^{t}[C H P](t) d t}{k_{3}^{\prime} \int_{0}^{t}[C H P](t) d t+k_{4} \int_{0}^{t}[C H P](t) d t+k_{-2}^{\prime} \int_{0}^{t}[C H P](t) d t}
\end{aligned}
$$


The same expression $\left(\int_{0}^{t}[C H P](t) d t\right)$ appears in all four terms on the right side of our equation. We don't know what this expression is equal to, but we can replace it with some constant $\Theta$. Since $\Theta$ appears in all four terms of the fraction, we can drop it from the derivation.

$$
\frac{[\text { phenol }]_{\text {final }}}{[\text { phenol }]_{\text {final }}+[A M S]_{\text {final }}+[D C P]_{\text {final }}}=\frac{k_{3}^{\prime} \Theta}{k_{3}^{\prime} \Theta+k_{4} \Theta+k_{-2}^{\prime} \Theta}=\frac{k_{3}^{\prime}}{k_{3}^{\prime}+k_{4}+k_{-2}^{\prime}}
$$

We can therefore calculate the expression $k_{3}^{\prime} /\left(k_{3}^{\prime}+k_{4}+k_{-2}^{\prime}\right)$ using the final species concentrations as measured by experiment. A similar treatment is possible for the other fraction of interest $\left(k_{2}^{\prime \prime} /\left(k_{2}^{\prime}+k_{2}^{\prime \prime}\right)\right)$.

Figure S10. (a) Derivation of the yield of phenol based on the expression of the mechanism of the acid-catalyzed decomposition of DCP. (b) Proof that a ratio of rate constants can be measured via measurement of the relevant final species concentrations.<smiles>BrC(I)c1ccccc1</smiles><smiles>[2H]C(Cl)(OOC(C)(C)c1ccccc1)c1ccc(Cl)cc1</smiles><smiles>CC(=O)I</smiles>

$\mathrm{t}$<smiles>Oc1ccccc1</smiles><smiles>[X]C1COCCO1</smiles><smiles>CC(=O)c1ccccc1</smiles>

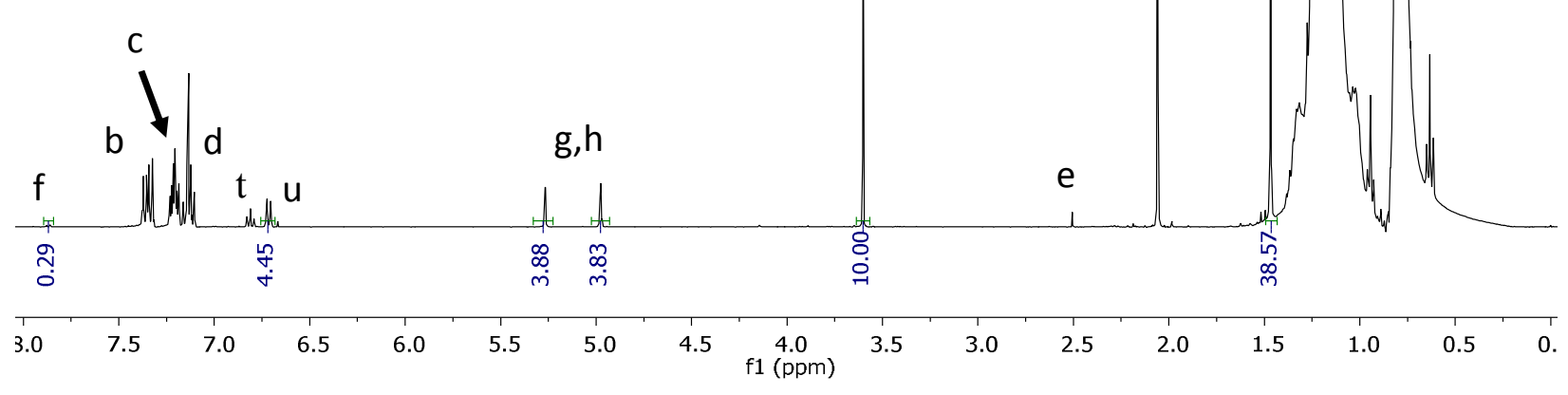

Figure S11. Proton NMR spectrum of the reaction of $0.0589 \mathrm{M}$ DCP with 0.03 eq DBSA in dodecane at $110{ }^{\circ} \mathrm{C}$ for 1 hour. Sample was diluted by a factor of 3 in $\mathrm{CDCl} 3$ for NMR analysis. Final sample contains 0.003398 M 1,4-dioxane as internal standard (added after reaction). 
Determination of final concentrations of DCP, ACP, phenol, and AMS after acid-catalyzed decompositions of DCP and CHP

Quantification was carried out via ${ }^{1} \mathrm{H}$ NMR with an internal standard. 1,4-dioxane (14DO) was employed as an ideal standard: it has only a single proton peak and that peak is distinct from the species of interest, as shown in Figure S11. A solution was prepared of $0.005090 \mathrm{M} 14 \mathrm{DO}$ in $\mathrm{CDCl}_{3}$. After reaction, samples were diluted with this solution at a ratio of 1 part reaction sample to 2 parts $14 \mathrm{DO}$ in $\mathrm{CDCl}_{3}$. The resulting final concentration of $14 \mathrm{DO}$ in solution was therefore $0.003393 \mathrm{M}$, which was used to determine the concentrations of other species in solution.

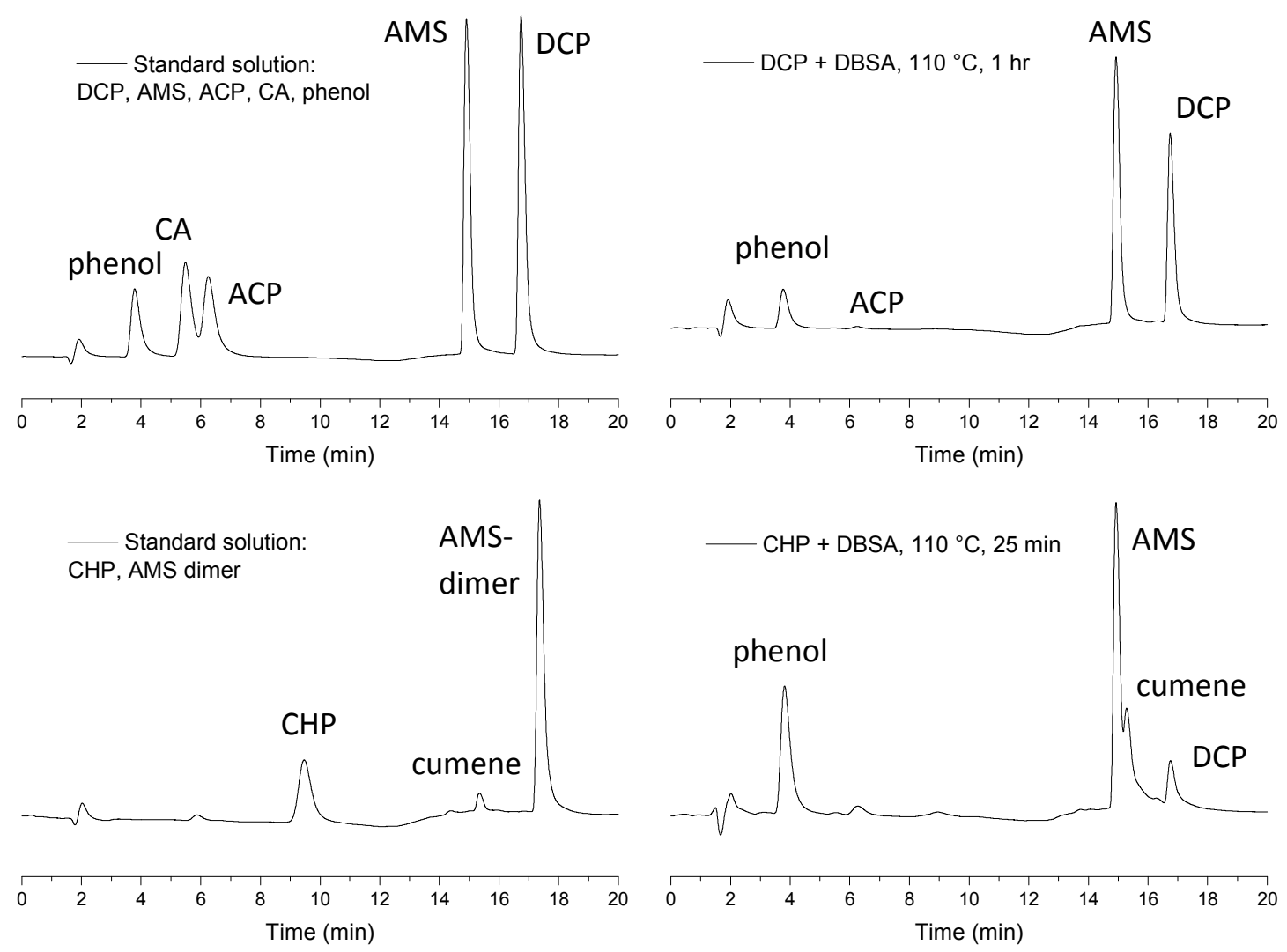

Figure S12. Representative HPLC chromatograms of the sealed reactions of 0.0589 M DCP +0.03 eq DBSA (top) and 0.0589 M CHP + 0.03 eq DBSA (bottom). 'AMS dimer' in the bottom-left corresponds to 2,4-diphenyl-4-methyl-1pentene (CAS 6362-80-7) which was purchased from Sigma-Aldrich and hypothesized to form during reaction. None of the examined reaction samples contained this species. Cumene is contained in the CHP stock. 


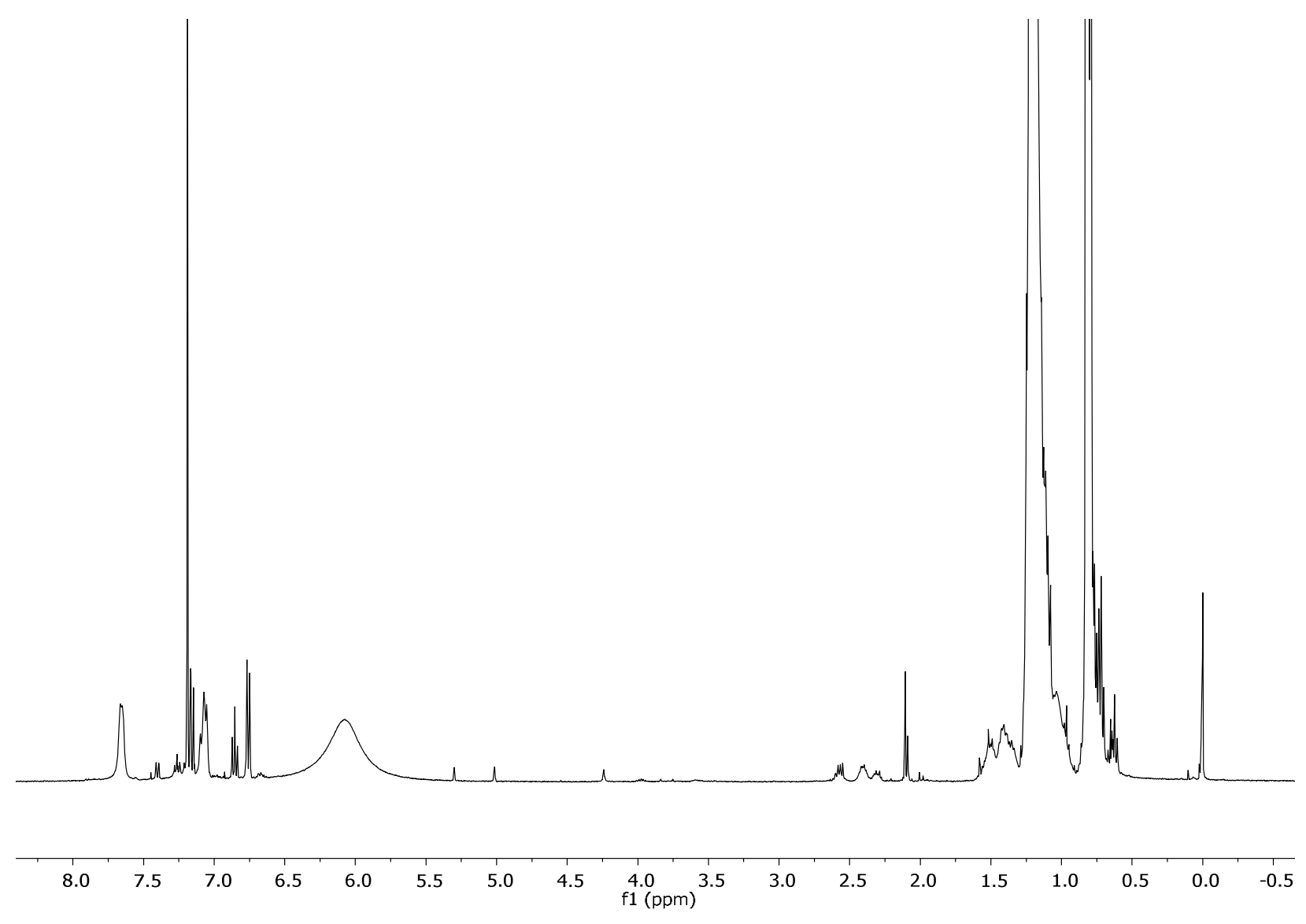

Figure S13. Proton NMR spectrum in $\mathrm{CDCl} 3$ of the brown precipitate left in the reaction vessel after the acid-catalyzed decomposition of DCP or CHP. Note the appearance of aromatic, vinyl, and various aliphatic proton peaks. 